\title{
The Prediction of Inadequate Colon Capsule Cleansing: A Cohort Selection Guided by CC-CLEAR
}

\author{
Rui de Sousa Magalhães a, b, c Pedro Boal Carvalho ${ }^{a, b}, c$ Bruno Rosa ${ }^{a, b}, c$ \\ Maria João Moreira ${ }^{a, b}, c$ José Cotter ${ }^{a, b}, c$ \\ ${ }^{a}$ Gastroenterology Department, Hospital Senhora da Oliveira, Guimarães, Portugal; ${ }^{b}$ Life and Health Sciences \\ Research Institute (ICVS), School of Medicine, University of Minho, Braga, Portugal; ' ICVS/3B's, PT Government \\ Associate Laboratory, Guimarães/Braga, Portugal
}

\section{Keywords}

CC-CLEAR · Colon capsule · Inadequate bowel cleansing · Predictive factors

\section{Abstract}

Introduction: In order to optimize the rate of adequate cleansing in colon capsule, it may be important to identify risk factors that can predict a suboptimal colon preparation. Aim: To define predictive factors for inadequate bowel preparation in colon capsule, according to CC-CLEAR (Colon Capsule CLEansing Assessment and Report). Methods: Retrospective, single center, cohort study. Patients' demographics, data, and quality of bowel preparation, according to CC-CLEAR, were collected retrospectively. A univariate analysis tested the association between covariables and the outcome, inadequate cleansing. The statistically significant variables were included in multivariable logistic binary regression, and a receiver operating characteristic curve (ROC) assessment was performed. Results: We included 167 consecutive colon capsules. Sixty-eight percent $(n=114)$ of patients were female, with a mean age of 64 years. The main indication for colon capsule was previous incomplete colonoscopy, in 158 patients (94.6\%). The colon capsules cleans- ing was graded as good or excellent in 96 patients (57.5\%) and as inadequate in 71 (42.5\%), according to CC-CLEAR. The variables inadequate previous colon cleansing (OR adjusted 41.72 [95\% Cl 12.57-138.57], $p$ value < 0.001); chronic laxative (OR adjusted 4.86 [95\% Cl 1.08-21.79], $p$ value $=0.039$ ); antidepressant (OR adjusted 5.00 [95\% Cl 1.65-15.16], $p$ value $=0.004$ ), and impaired mobility (OR adjusted $5.54[95 \% \mathrm{Cl}$ 1.17-26.31], $p$ value $=0.031$ ) were independently associated with the outcome inadequate cleansing, after adjusting for confoundment. The model presented an excellent discriminative power towards the outcome variable (AUC ROC 0.937 [Cl 95\% 0.899-0.975], $p$ value < 0.001). Conclusion: A previous inadequate colon cleansing, the use of chronic laxative and antidepressant, or impaired mobility are predictors of inadequate colon capsule cleansing, as assessed by the CCCLEAR. These 4 predictors come together as a model enabling an accurate categorization of the patients at major risk of inadequate bowel preparation for capsule colonoscopy, with an excellent discriminative power and performance, which seems useful for the selection of patients for tailored optimization of the colon cleansing protocol.

(c) 2021 Sociedade Portuguesa de Gastrenterologia Published by S. Karger AG, Basel

Correspondence to:

Rui de Sousa Magalhães, rui.magalhaes.med@gmail.com karger@karger.com www.karger.com/pjg

Karger $\stackrel{\text { ' }}{5}$

BOPEN ACCESS (c) 2021 Sociedade Portuguesa de Gastrenterologia Published by S. Karger AG, Basel

This is an Open Access article licensed under the Creative Commons Attribution-NonCommercial-4.0 International License (CC BY-NC) (http://www.karger.com/Services/OpenAccessLicense), applicable to the online version of the article only. Usage and distribution for commercial purposes requires written permission. 
Fatores preditivos de preparação intestinal inadequada em cápsula do colon: uma coorte guiada pela CC-CLEAR

\section{Palavras Chave}

CC-CLEAR · Cápsula do colon · Preparação intestinal inadequada $\cdot$ Fatores preditores

\section{Resumo}

Introdução: Com o intuito de otimizar a taxa de preparações intestinais adequadas em cápsula do cólon, poderá ser importante identificar fatores de risco preditivos de preparações sub-ótimas. Objetivo: Definir fatores preditivos de preparação intestinal inadequada em cápsula do colon, de acordo com a CC-CLEAR (Colon Capsule CLEansing Assessment and Report). Métodos: Estudo de coorte retrospetivo, no qual as variáveis demográficas, clínicas e a qualidade de preparação intestinal, de acordo com a CCCLEAR, foram colhidas retrospetivamente. Uma análise univariada testou a associação entre as covariáveis e a variável outcome - preparação intestinal inadequada. As variáveis estatisticamente significativas foram incluídas num modelo de regressão logística binária e performance testada com a realização de curva ROC. Resultados: Incluímos 167 cápsulas do colon consecutivas. Sessenta e oito por cento $(n=114)$ eram do sexo feminino, com idade média de 64 anos. A principal indicação para cápsula do colon foi uma colonoscopia prévia incompleta, em 158 indivíduos (94.6\%). As preparações intestinais em cápsula do colon foram classificadas como boas ou excelentes em 96 indivíduos (57.5\%) e como inadequadas em 71 (42.5\%), de acordo com a CC-CLEAR. As variáveis preparação cólica prévia inadequada [OR ajustado 41.72 (95\% Cl 12.57138.57) valor $p<0.001$ ]; uso crónico de laxante [OR ajustado 4.86 (95\% Cl 1.08-21.79) valor $p=0.039]$; antidepressivo [OR ajustado $5.00(95 \% \mathrm{Cl} 1.65-15.16)$ valor $p=0.004$ ] e défice de mobilidade [OR ajustado 5.54 (95\% Cl 1.1726.31 ) valor $p=0.031]$ foram independentemente associadas ao outcome, preparação intestinal inadequada, após o ajuste para o confundimento. $\mathrm{O}$ modelo apresentou um excelente poder discriminativo em relação ao outcome [AUC ROC 0.937 (CI95\% 0.899-0.975) valor $p<$ 0.001]. Conclusão: Uma preparação cólica prévia inadequada, o uso crónico de laxantes e antidepressivos e um défice de mobilidade são preditores de preparação intestinal inadequada em cápsula do cólon, de acordo com a CC-CLEAR. Estas 4 variáveis formam um modelo que permite a categorização, com excelente acuidade, de indi- víduos com risco elevado para preparação intestinal inadequada em cápsula do colon, o que parece ser útil para uma otimização caso a caso do protocolo de preparação intestinal.

(c) 2021 Sociedade Portuguesa de Gastrenterologia Publicado por S. Karger AG, Basel

\section{Introduction}

Colonoscopy is the standard examination for colorectal cancer screening and the investigation of colonic diseases [1]. Quality parameters are key to improve colonoscopy efficacy and safety, and factors such as an appropriate colonoscopy indication, the obtention of patients' informed consent, an appropriate adenoma detection rate (ADR), and an adequate bowel cleansing are some of the several points that should be checked regularly to achieve a proper quality colonoscopy [1]. The European Society of Gastrointestinal Endoscopy (ESGE) recommends a minimum of $90 \%$ procedures with adequate bowel cleansing [2], being that an inadequate bowel preparation is associated with the need to repeat colonoscopy, lower cecal intubation rates, unsatisfactory patient experience, and lower ADR [3].

Colon capsule (CC) is a minimally invasive procedure, with established indications, such as incomplete conventional colonoscopy, suspected lower GI bleeding, and inflammatory bowel disease [4], that is gaining recognition in the field of colorectal cancer screening [5]. For CC to be as viable as conventional colonoscopy, quality performance criteria are a matter of diligent importance and must be adapted and further evaluated. Regarding colon cleansing, our group recently took a step further by creating the Colon Capsule CLEansing Assessment and Report (CC-CLEAR) [6], allowing a standardized bowel cleansing reporting for $\mathrm{CC}$, aiming to improve the quality of examinations as a support for clinical decisions and research reliability and validity. From a practical point of view, to achieve adequate colon cleansing in CC is challenging, since, for instance, intraprocedural actions aiming to improve bowel cleansing, such as "washing" and "aspiration" are not available when compared with conventional colonoscopy. An inadequate bowel cleansing will exponentially hamper the colonic lumen and mucosa visualization in CC setting. Therefore, being able to identify the subgroup of patients that will mostly benefit from an optimized and stricter cleansing protocol would be a benefit when striving to optimize the rate of adequate bowel cleansing in CC. The ability to improve the odds of obtaining adequate $\mathrm{CC}$ bowel cleansings will lead to low- 
er need for repeated examinations and ultimately a better allocation of healthcare resources. We aim to define predictive factors for inadequate bowel preparation in CC, guided by the CC-CLEAR.

\section{Methods}

We designed a retrospective cohort study including consecutive patients submitted to CC endoscopy, in the Gastroenterology Department of a University-Affiliated Hospital. This department is a center of excellence for capsule endoscopy and highly experienced. The study protocol conforms to the ethical guidelines of the 1975 Declaration of Helsinki. All patients signed an informed consent form and consensual contraindications for CC procedure were respected.

\section{Participants}

The participants included underwent CC from January 2015 until March 2021. The inclusion criteria were as follows: all adult patients ( $\geq 18$ years old) who underwent CC endoscopy, regardless of clinical indication or comorbidities, with a complete procedure, meaning capsule exteriorization or at least visualization of the hemorrhoid pedicles within battery time. Exclusion criteria were pregnancy, known or suspected GI obstruction, incomplete procedures, CC with a colonic transit time inferior to $45 \mathrm{~min}$, and patients not tolerating the ingestion of at least $75 \%$ of the bowel preparation regimen. Figure 1 represents the cohort's exclusion criteria flowchart (Fig. 1).

\section{Preparation}

Bowel preparation was performed according to our center's protocol [7-9]. Patients were instructed to have a low-fiber diet and ingest at least 10 glasses of water 2 days before the procedure. On the day before the procedure, a clear liquid diet was prescribed, as well as $1 \mathrm{~L}$ of polyethylene glycol (PEG) solution plus ascorbate followed by $1 \mathrm{~L}$ of water between 7 and 9 p.m. On the day of the procedure, another $1 \mathrm{~L}$ of this solution followed by $1 \mathrm{~L}$ of water was ingested (between 6:30 and 8:30 a.m.), and fasting was warranted afterward. Thirty minutes before capsule ingestion, patients were given $100 \mathrm{mg}$ of simethicone. At 9 a.m., patients were instructed to ingest the capsule. One hour later, using the real-time viewing system, capsule progression to the small bowel was confirmed, and $10 \mathrm{mg}$ of domperidone was administered if the capsule was still in the stomach. Thirty minutes later, capsule progression was assessed, and in the case of delayed stomach emptying, endoscopic capsule placement in the small bowel was performed. When the small bowel was reached, a booster of $30 \mathrm{~mL}$ of sodium phosphate solution (Fleet Phospho Soda; Casen-Fleet Laboratories, Madrid, Spain) was administered, followed by ingestion of $1 \mathrm{~L}$ of water; $3 \mathrm{~h}$ later, the second booster of sodium phosphate $(15 \mathrm{~mL})$ was administered, plus $500 \mathrm{~mL}$ of water. After another $2 \mathrm{~h}$, if the capsule was not excreted, a bisacodyl suppository was given (Fig. 2).

\section{Capsule Reporting and CC-CLEAR Cleansing Scale}

All procedures were performed with the PillCam ${ }^{\circledR}$ COLON 2 capsule (Medtronic, Minneapolis, MN, USA). Complete CC videos were reviewed by 2 independent experienced physicians (over 500 examinations) using the Rapid ${ }^{\circledR}$ Reader software version 9.0,

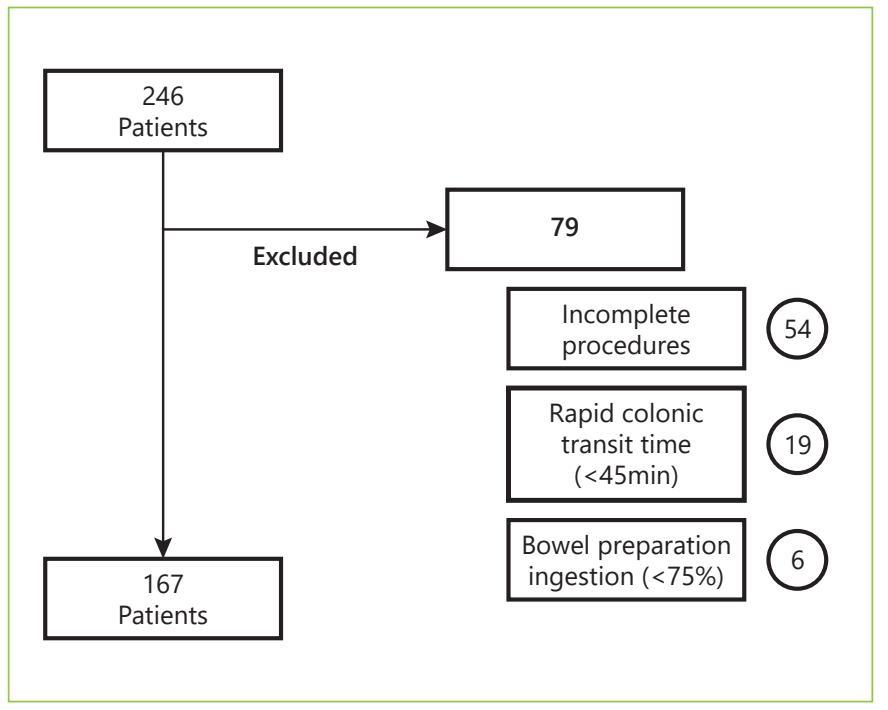

Fig. 1. Flowchart representing the cohort process of exclusion.

in "twin head mode," including both camera views from the CC displayed on-screen simultaneously at a rate of 8-15 frames per second $[10,11]$. CC bowel cleansing was classified according to the CC-CLEAR scale [6]. Colon was divided into 3 segments as follows, right-sided, transverse, and left-sided colon, keeping in mind the main colon landmarks (hepatic and splenic flexures), and each segment was classified according to an estimation of the percentage of mucosa clearly visualized ( 0 points, $<50 \%$; 1 point, $50-75 \%$; 2 points, $>75 \%$; 3 points, $>90 \%$ ), taking into account solid debris, clarity of liquid, and bubbles, which could compromise an adequate visualization. The overall cleansing classification was based on the sum of each segment's score, grading between inadequate ( $0-5$ points), good (6-7 points), and excellent ( $8-9$ points). If any segment presented a classification of 1 or less, the overall classification given was inadequate, independent of the overall score punctuation.

\section{Data and Variable Definition}

The primary outcome variable was an inadequate bowel cleansing according to the CC-CLEAR cleansing scale (overall scoring of less than 6 points or at least 1 segment scoring less than 2 points). Co-variables included demographic characteristics, namely, age (collected as continuous variable and nominal variable, according to the cut-off 65 years old) and gender, grade of education (according to the cut off 9 th grade of school education). We also assessed cohort comorbidities, including, multiple comorbidities (more than 3 chronic diseases), previous diagnosis of dementia, diabetes mellitus, obesity (IMC $\geq 30$ ), previous history of abdominal surgery and impaired mobility (diagnosed by an expert physician, and meaning the need of external help for daily basis activities). We also assessed chronic constipation (diagnosed by an expert gastroenterologist, according to clinical history and physical examination [12, 13], keeping in mind the ROME criteria [14]), previous inclusion in a cleansing protocol, and CC and/or colonoscopy reporting inadequate bowel cleansings (regarding the latter, according to the Boston Bowel Preparation Scale [15]). Regarding drugs, we considered poly-medication (more than 3 drugs taken on a dai- 


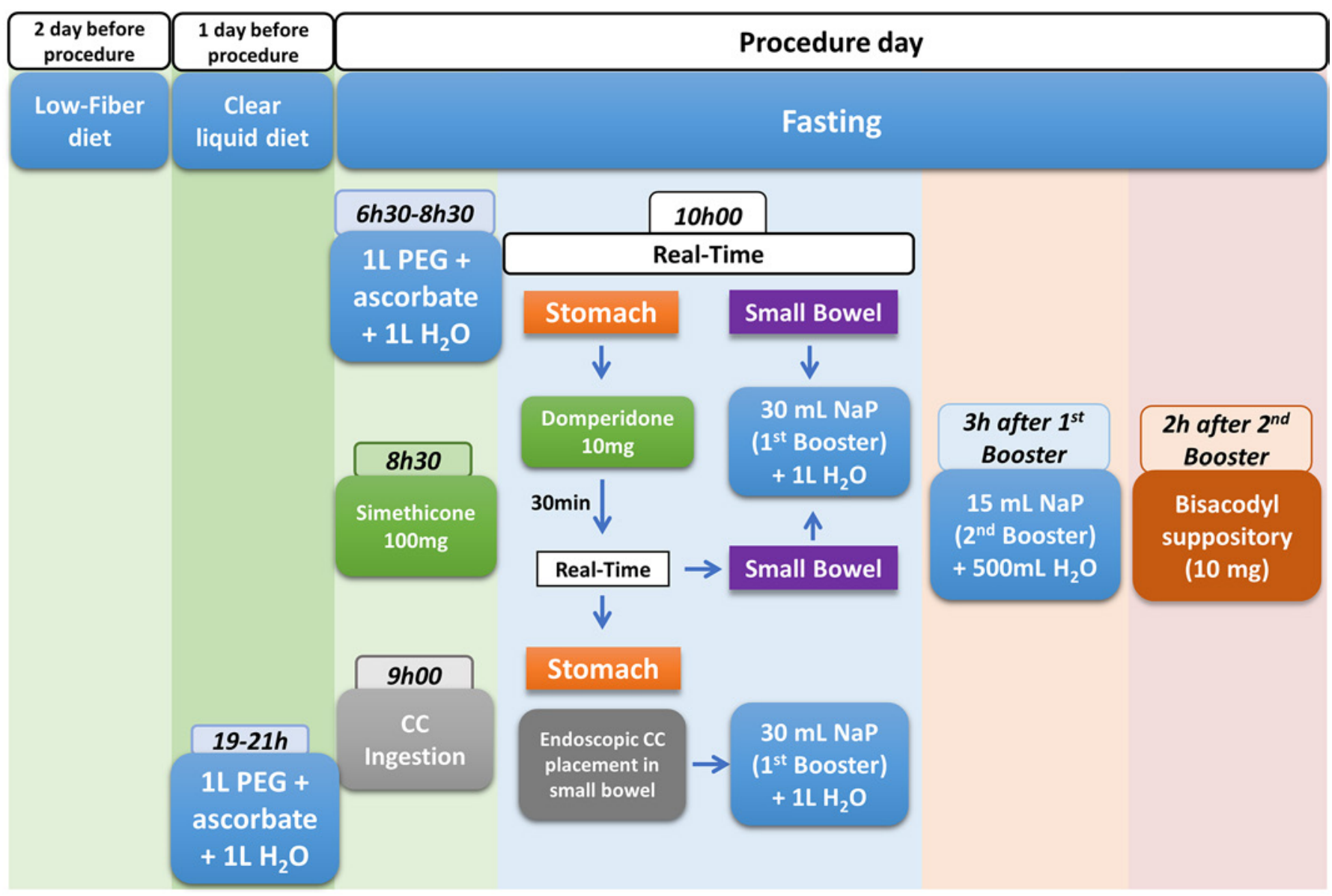

Fig. 2. The colon capsule cleansing protocol currently in practice in our Gastroenterology Department. CC, colon capsules; PEG, polyethylene glycol; $\mathrm{NaP}$, sodium phosphate solution.

ly basis), taking chronic laxatives, opioid drugs, calcium channel blockers, and antidepressants (selective serotonin reuptake inhibitor, serotonin-norepinephrine reuptake inhibitor, and tricyclic antidepressant). We also evaluated whether the patient was admitted to the hospital at the moment of CC, CC indication, CC-related complications, colonic transit time (meaning the time from the first image of the cecum until the exteriorization or at least visualization of the hemorrhoid pedicles, measured in minutes) and CCCLEAR cleansing scale (measured as continuous variable - the final overall scoring per capsule; and as nominal variable - inadequate versus adequate classification, the latter considering all capsules not meeting the criteria for inadequate cleansing).

\section{Statistical Analysis}

Categorical variables were described using absolute frequencies and percentages, while continuous variables were described using medians and interquartile ranges. We compared the frequency of inadequate bowel cleansing according to the different collected variables. Categorical variables were analyzed using Fisher's exact test or $\chi^{2}$ test, as appropriate. Continuous variables were analyzed using Student's $t$ test or Mann-Whitney U test. Independent variables with statistical association with the outcome variable $(p<0.005)$ in univariable analysis were simultaneously tested in a multivariable logistic regression model. In order to avoid the inclusion of an excess number of variables in relation to our sample size (with 71 inadequate bowel cleansings, and considering a need for $10-15$ events per covariate, no $>5$ covariates should be simultaneously introduced in the model), we included 5 covariates, keeping in mind clinical value, easy applicability and the crude univariate odds ratio. We assessed the performance of the multivariate final model for the prediction of inadequate bowel cleansing by means of a receiver operating characteristic curve (ROC) - we determined the area under the curve (AUC-ROC) and the respective 95\% CI. Statistical analysis was performed with SPSS version 26.0 (IBM, Armonk, NY, USA). All reported $p$ values are 2 -tailed, with $p<0.05$ indicating statistical significance.

\section{Results}

We included 167 consecutive CCs, from 2015 to 2020. Sixty-eight percent $(n=114)$ were female, with a mean age of 64 years. The main indication for CC was incomplete colonoscopy, in 158 patients (94.6\%). The CC 
Table 1. Descriptive analysis of all variables included

\begin{tabular}{|c|c|}
\hline Variable & Total $(n=167)$ \\
\hline Age, mean (SD), years & $64.07(14.45)$ \\
\hline \multicolumn{2}{|l|}{ Age, $n(\%)$} \\
\hline$>65$ years & $72(43.1)$ \\
\hline$<65$ years & $95(56.9)$ \\
\hline \multicolumn{2}{|l|}{ Gender, $n$ (\%) } \\
\hline Male & $53(31.7)$ \\
\hline Female & $114(68.3)$ \\
\hline CC complications, $n$ (\%) & $0(0)$ \\
\hline \multicolumn{2}{|l|}{ CC indication, $n(\%)$} \\
\hline Incomplete conventional colonoscopy & $158(94.6)$ \\
\hline Crohn's disease staging & $8(4.8)$ \\
\hline Anemia & $1(0.6)$ \\
\hline CC-CLEAR, mean (SD), points & $5.95(2.30)$ \\
\hline \multicolumn{2}{|l|}{ CC-CLEAR classification, $n(\%)$} \\
\hline Adequate (good and excellent) & $96(57.5)$ \\
\hline Inadequate & $71(42.5)$ \\
\hline \multicolumn{2}{|l|}{ Previous colon cleansing, $n(\%)$} \\
\hline Yes & $163(97.6)$ \\
\hline No & $4(2.4)$ \\
\hline \multicolumn{2}{|c|}{ Previous colon cleansing classification, $n(\%)^{\mathrm{a}}$} \\
\hline Adequate & $106(63.5)$ \\
\hline Inadequate & $57(34.1)$ \\
\hline Colonic transit time, mean (SD), min & $295.30(215.42)$ \\
\hline \multicolumn{2}{|l|}{ Chronic constipation, $n(\%)$} \\
\hline Yes & $50(29.9)$ \\
\hline No & $117(70.1)$ \\
\hline \multicolumn{2}{|l|}{ Grade of education, $n(\%)$} \\
\hline Above 9th grade & $97(58.1)$ \\
\hline Below 9th grade & $70(41.9)$ \\
\hline \multicolumn{2}{|l|}{ Dementia, $n(\%)$} \\
\hline Yes & $3(1.8)$ \\
\hline No & $164(98.2)$ \\
\hline \multicolumn{2}{|l|}{ Admitted to the hospital, $n(\%)$} \\
\hline Yes & $3(1.8)$ \\
\hline No & $164(98.2)$ \\
\hline
\end{tabular}

cleansing was graded as good or excellent in 96 patients $(57.5 \%)$ and as inadequate in $71(42.5 \%)$, according to CC-CLEAR. Table 1 lists the descriptive analysis of all variables included. Table 2 lists the results of the univariable analysis and the crude odds ratio comparing patients who presented an inadequate bowel cleansing versus the remaining. The following variables presented statistically significant association with inadequate bowel cleansing (Table 2): previous inadequate colon cleansing classification $(p<0.001$; OR crude 41.56 [95\% CI 15.50-111.41], $p$ value $<0.001)$; chronic constipation $(p<0.001$; OR crude 31.50 [95\% CI 11.34-87.49], $p$ value $<0.001)$; grade of education $(p=0.009$; OR crude 0.43 [95\% CI 0.23-0.42], $p$ value 0.01 ); poly-medication ( $p=0.001$; OR crude 2.82 [95\% CI 1.49-5.34], $p$ value 0.001); calcium channel

\begin{tabular}{|c|c|}
\hline Variable & Total $(n=167)$ \\
\hline \multicolumn{2}{|c|}{ Poly-medication, $n$ (\%) } \\
\hline Yes & $68(40.7)$ \\
\hline No & $99(59.3)$ \\
\hline \multicolumn{2}{|c|}{ Opioids, $n(\%)$} \\
\hline Yes & $2(1.2)$ \\
\hline No & $165(98.8)$ \\
\hline \multicolumn{2}{|c|}{ Calcium channel blockers, $n(\%)$} \\
\hline Yes & $24(14.4)$ \\
\hline No & $143(85.6)$ \\
\hline \multicolumn{2}{|c|}{ Chronic laxative, $n(\%)$} \\
\hline Yes & $36(21.6)$ \\
\hline No & $131(78.4)$ \\
\hline \multicolumn{2}{|c|}{ Antidepressant, $n(\%)$} \\
\hline Yes & $60(35.9)$ \\
\hline No & $107(64.1)$ \\
\hline \multicolumn{2}{|c|}{ Obesity (BMI >30), $n(\%)$} \\
\hline Yes & $8(4.8)$ \\
\hline No & $159(95.2)$ \\
\hline \multicolumn{2}{|c|}{ Diabetes mellitus, $n(\%)$} \\
\hline Yes & $31(18.6)$ \\
\hline No & $136(81.4)$ \\
\hline \multicolumn{2}{|c|}{ Multiple chronic comorbidities (>3), $n(\%)$} \\
\hline Yes & $51(30.5)$ \\
\hline No & $116(69.5)$ \\
\hline \multicolumn{2}{|c|}{ Previous abdominal surgery, $n(\%)$} \\
\hline Yes & $63(37.7)$ \\
\hline No & $104(62.3)$ \\
\hline \multicolumn{2}{|c|}{ Impaired mobility, $n$ (\%) } \\
\hline Yes & $28(16.8)$ \\
\hline No & $139(83.2)$ \\
\hline
\end{tabular}

SD, standard deviation; ${ }^{\text {a }}$ Four missing values (patients without previous colon cleansing). blockers ( $p<0.001$; OR crude 6.65 [95\% CI 2.35-18.86], $p$ value $<0.001)$; chronic laxative $(p<0.001$; OR crude 10.98 [95\% CI 4.24-28.41], $p$ value $<0.001)$; antidepressant $(p<0.001$; OR crude 4.35 [95\% CI 2.22-8.53], $p$ value $<0.001)$; multiple chronic comorbidities $(p<0.001$; OR crude 4.86 [95\% CI 2.39-9.89], $p$ value $<0.001)$; previous abdominal surgery $(p<0.001$; OR crude 4.09 [95\% CI 2.11-7.95], $p$ value $<0.001)$; impaired mobility $(p<$ 0.001 ; OR crude 8.72 [95\% CI 3.12-24.39], $p$ value < $0.001)$; and colonic transit time $(p=0.014$; OR crude 1.002 [95\% CI 1.000-1.003], $p$ value 0.017). Five co-variables were included in the multivariate logistic regression model, keeping in mind clinical value, easy applicability, and the crude univariate odds ratio. Table 3 lists the covariables included in the multivariate logistic model. The 
Table 2. Results of the univariable analyses and crude odds ratio assessing the potential association between patients' demographic, clinical, and laboratory variables and the occurrence of inadequate bowel cleansing according to CC-CLEAR

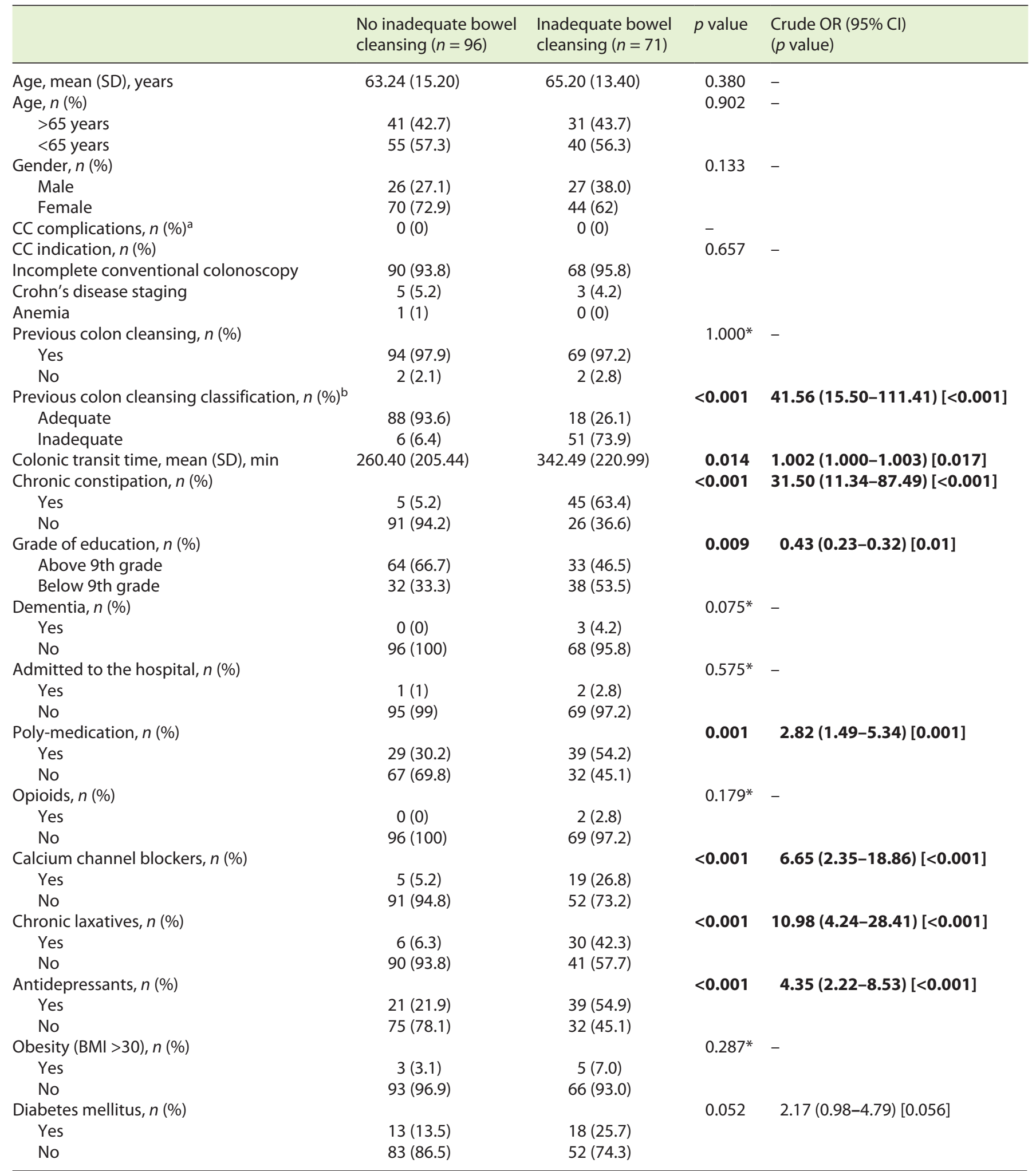


Table 2 (continued)

\begin{tabular}{|c|c|c|c|c|}
\hline & $\begin{array}{l}\text { No inadequate bowel } \\
\text { cleansing }(n=96)\end{array}$ & $\begin{array}{l}\text { Inadequate bowel } \\
\text { cleansing }(n=71)\end{array}$ & $p$ value & $\begin{array}{l}\text { Crude OR }(95 \% \mathrm{Cl}) \\
\text { ( } p \text { value) }\end{array}$ \\
\hline Multiple chronic comorbidities (>3), $n$ (\%) & & & $<0.001$ & $4.86(2.39-9.89)[<0.001]$ \\
\hline No & $80(80.3)$ & $36(50.7)$ & & \\
\hline Previous abdominal surgery, $n$ (\%) & & & $<0.001$ & $4.09(2.11-7.95)[<0.001]$ \\
\hline Yes & $23(24.0)$ & $40(56.3)$ & & \\
\hline Yes & $5(5.2)$ & $23(32.4)$ & & \\
\hline No & $91(94.8)$ & $48(67.6)$ & & \\
\hline
\end{tabular}

CC, colon capsule; SD, standard-deviation; BMI, body mass index. ${ }^{\text {a }}$ No statistic was calculated cause the variable complication is a constant. ${ }^{\mathrm{b}} 4$ missing values, number of patients without previous colon cleansing. ${ }^{*}$ Fisher's exact test.

Table 3. Results of the multivariable logistic regression analyses assessing the association between patients' co-variables and the occurrence of inadequate bowel cleansing according to CC-CLEAR in the colon capsule

\begin{tabular}{|c|c|c|}
\hline & Adjusted OR (95\% Cl) & $p$ value \\
\hline Previous colon cleansing classification & $41.72(12.57-138.54)$ & $<0.001$ \\
\hline Chronic laxative & $4.86(1.08-21.79)$ & 0.039 \\
\hline Calcium channel blockers & $4.14(0.91-18.82)$ & 0.066 \\
\hline Antidepressant & $5.00(1.65-15.16)$ & 0.004 \\
\hline Impaired mobility & $5.54(1.17-26.31)$ & 0.031 \\
\hline
\end{tabular}

following variables remained statistically associated with the outcome (inadequate bowel cleansing): previous inadequate colon cleansing (OR adjusted 41.72 [95\% CI 12.57-138.57], $p$ value $<0.001$ ); chronic laxative (OR adjusted 4.86 [95\% CI 1.08-21.79], $p$ value $=0.039$ ); antidepressant (OR adjusted 5.00 [95\% CI 1.65-15.16], $p$ value $=0.004)$ and impaired mobility (OR adjusted 5.54 [95\% CI 1.17-26.31], $p$ value $=0.031$ ). By means of a ROC, we tested the performance of the model. The model presented an excellent discriminative power and optimal accuracy when tested against the outcome variable, as indicated by the area under curve (AUC) of the ROC in Figure 3 (AUC-ROC 0.937 [95\% CI 0.899-0.975], $p$ value $<0.001)$.

\section{Discussion}

An adequate bowel cleansing is the cornerstone for a high-quality colonoscopy, impacting the examination diagnostic efficiency and being crucial for optimal colonic visualization $[1,2]$. For a reliable $\mathrm{CC}$, an adequate colon cleansing is even more indispensable, since intraprocedural actions aiming to improve bowel cleansing, such as "washing" and "aspiration" are not available

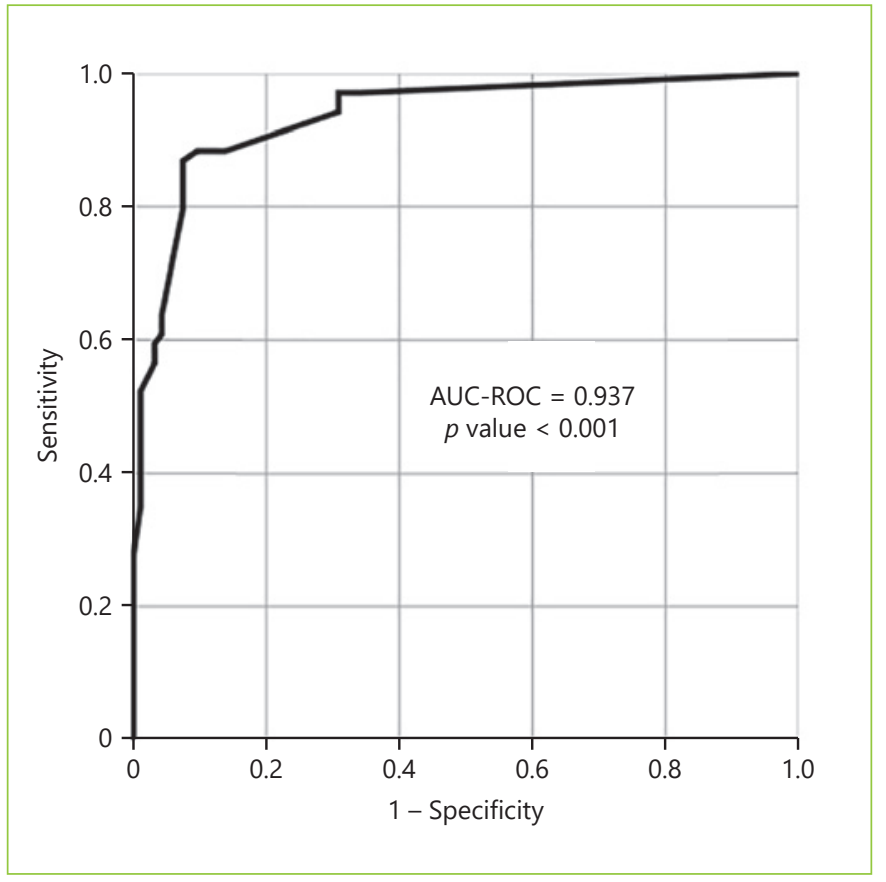

Fig. 3. ROC testing the accuracy of the multivariate logistic regression model in identifying patients with an inadequate cleansing colon classification, according to the CC-CLEAR. AUC, area under the curve; ROC, receiver operating characteristic curve. 
when compared with conventional colonoscopy. We are also unable to modify the patients' position, insufflate the colonic lumen, and, since CC is not operator dependent, we lack motion control over the twin-head camera direction. These conditions make an inadequate bowel cleansing in CC a factor that exponentially hampers overall examination quality when compared with conventional colonoscopy. Therefore, we can only rely on preprocedural modifiable aspects to optimize CC bowel cleansing.

We included 167 consecutive CCs, 71 (42.5\%) graded with inadequate bowel cleansing, according to CCCLEAR. The comparison with the literature reported cleansing rates is biased, mainly due to the overwhelming subjectivity associated with previous CC bowel cleansing classifications. For instance, Spada et al. [16] reported CC inadequate preparation in $57.5 \%$ of cases and Kastenberg et al. [17] in $24.1 \%$ of cases. For conventional colonoscopy, the rates of inadequate bowel cleansing are also widely variable and go from 12 up to $50 \%$ [18-22].

With the guidance of the CC-CLEAR to optimize result reliability [6], we were able to report independent predictive risk factors for an inadequate colon cleansing in CC. A previous inadequate colon cleansing, impaired patient mobility, and chronic usage of antidepressants and laxatives were the independent factors that showed a correlation towards an inadequate bowel cleansing in CC. The final model including these variables showed an excellent discriminative power and optimal accuracy in predicting inadequate bowel cleansing, by means of an AUC-ROC of 0.937 (CI 95\% 0.899-0.975; $p$ value < $0.001)$. The literature is scarce in the topic of predicting inadequate bowel cleansing in CC. However, several studies have been published regarding the prediction of inadequate bowel preparation for conventional colonoscopy, reporting similar predictive factors. In their multicenter observational study that included 1,032 patients, Fuccio et al. [18] reported that meetings with physician, educational instructions in bowel preparation, admission to gastroenterology unit, split-dose regimens, the usage of 1 L PEG-based preparation, and the ingestion of at least $75 \%$ of bowel purge were associated with adequate bowel cleansing. On the other hand, a bedridden status, constipation, diabetes mellitus, use of antipsychotic drugs, and 7 or more days of hospitalization were associated with inadequate bowel cleansing. Dik et al. [19] studied a cohort of 1,331 colonoscopies, and concluded that an ASA score $\geq 3$, chronic use of tricyclic antidepressants and opioids, diabetes mellitus, chronic constipation, previous abdominal surgery, previous inadequate bowel preparation, and current hospitalization were factors associated with inadequate bowel cleansing, reporting a good model discriminative power with an AUC-ROC of 0.77. Yadlapati et al. [20], from a cohort of 524 patients, reported that a lower income, chronic opiate or tricyclic antidepressant, afternoon colonoscopy, an ASA class $\geq 3$ and nausea/vomiting were related to inadequate preparation. Gimeno-Garcia et al. [21] developed a predictive model for inadequate bowel preparation, from a cohort of 541 patients, based on antidepressants, comorbidity, constipation, and previous abdominal surgery (AUC-ROC of 0.72). Garber et al. [22], concluded based on 8,819 colonoscopies that opiate use, colonoscopy after 12:00 p.m., and solid diet the day before colonoscopy are related to inadequate bowel cleansing. They recommend avoiding opiates before colonoscopy, performing colonoscopy before noon, and maintaining patients on a liquid diet to reduce inadequate bowel cleansing rates in $5.6 \%$. In conclusion, and concerning the predictive model proposed in this study, including the variables previous inadequate colon cleansing, impaired mobility, chronic usage of antidepressant and laxative, it is reasonable to assume that there is a predictive factor overlap when compared with conventional colonoscopy studies.

A rather consistent predictive factor is chronic constipation, and we deem it necessary to explain the rationale behind the option to withdraw the diagnosis of chronic constipation from our final model. Chronic constipation is a very common gastrointestinal disorder with a prevalence of almost $20 \%$ in the general population [23], and as stated above, it is associated with higher rates of inadequate bowel cleansing. Guo et al. [24] reported that more than $1 / 3$ of patients with functional constipation had inadequate bowel cleansing. Nevertheless, chronic constipation is very challenging to diagnose [12], and to avoid variable overlap, since a large proportion of patients with chronic constipation consume laxatives, we opted to include chronic laxative usage instead, as it is an easier and more reliable variable to evaluate, whilst still selecting patients at a higher probability of inadequate bowel cleansing.

We propose an accurate model to select patients for an optimization of the CC preparation protocol, recognizing, however, that this optimization is per se a controversial topic.

PEG-based purges seem to be safer and more efficient when compared to non-PEG ones. In conventional colonoscopy, low volume (2 L) PEG also seems to be as 
efficient as large volume purges $(4 \mathrm{~L})$ and is better tolerated by patients [25]. In the setting of CC, controversy surrounds the efficacy of low-volume PEG purgatives. Argüelles-Arias et al. [26], in a head-to-head comparison study with a 4 L PEG protocol, proposed the addition of ascorbic acid to a 2 L PEG purgative, reporting better rates of adequate preparations and complete procedures. Vuik et al. [5], in a recent systematic review, reported a rate of CC adequate colon cleansings up to $92 \%$ for $4 \mathrm{~L}$ PEG formulations compared to $70 \%$ for lowvolume PEG protocols. The current CC ESGE guidelines still recommend classic 4 L PEG formulations [4]. For CC to remain a patient appealing procedure, the balance between cleansing protocol tolerability and efficacy is thin, but nevertheless, when striving for optimal CC cleansings, conventional high-volume PEG-based purges could be a reasonable recommendation. Since CCs are usually early morning examinations, the split-dose regimen is the most efficient and tolerated protocol timing to recommend [27]. Regarding diet, a low-fiber diet a day before the conventional colonoscopy seems to be as efficient as a clear liquid diet for cleanliness levels and encompasses better patient adhesion and satisfaction [28]. However, evidence is scarce concerning CC, and a clear diet the day before the procedure is associated with a higher diagnostic yield [4]. In selected cases, the recommendation of a clear diet for 2 or more days before the procedure may be a strategy to implement [16]. Adjunctive drugs are proven essential to improve overall cleanliness and capsule expulsion, and some are already a part of our regular preparation protocol, namely, ascorbic acid, simethicone (100 mg), prokinetics (domperidone $10 \mathrm{mg}$ ), a booster of $45 \mathrm{~mL}$ of sodium phosphate solution, as well as bisacodyl suppository on the procedure day [29]. In patients at higher risk for inadequate CC cleansing, it would be reasonable to assume a benefit from the implementation of laxatives a day or 2 before the procedure, such as, bisacodyl or senna tablets. Spada et al. [16] suggested that the inclusion of 4 senna tablets the day before procedure was safe and effective. In conventional colonoscopy, a bisacodyl (10 mg) suppository administered $2 \mathrm{~h}$ before the start of bowel cleansing allowed the reduction of PEG purgative volume with similar cleansing efficiency and increasing patient compliance [30,31]. Specifically, regarding chronic obstipation, the inclusion of an oral lactulose solution (30 mL) 1 day before colonoscopy [32], or rectal fleet enemas (sodium hydrogen phosphate and disodium hydrogen phosphate) prior to oral purgative may increase colon cleansing [33].

Predicting Inadequate Cleansing in Colon

Capsule Guided by CC-CLEAR
Additionally, and regarding modifiable aspects, we recommend implementing educational sessions, guided by physicians, to approach the cleansing protocols. In a recent meta-analysis, Gkolfakis et al. [34] concluded that education over the bowel preparation regimen improves adequate bowel preparation rates, from 50 up to $77 \%$.

Captivating patients' adhesion towards the cleansing preparation should also be a priority. Adjunct agents to improve patients' experience may have a role in increasing palatability, without hampering cleansing levels, namely, substituting water for orange juice, pineapple juice or green tea, and the inclusion of gum chewing and menthol candy drops [35].

It is key to understand that the ideal bowel preparation regimen for CC remains to be determined, and no single intervention has been proven to be optimal. We may only assume that combined optimization strategies will potentially improve the final CC cleanliness.

We acknowledge some limitations of the present study, namely its retrospective design, the single hospital center nature and the absence of an external validation for comparison. We recognize that further multicentric, prospective validation of the CC-CLEAR, and its influence in daily clinical practice will strengthen our results.

However, this article also presents several strong points. First, it raises awareness towards the importance of establishing quality criteria for an optimal capsule colonoscopy. To our knowledge, this is the first study addressing the topic of inadequate colon cleansing prediction in the setting of $\mathrm{CC}$, based on the new cleansing reporting scale, the CC-CLEAR, a quantitative objective scoring index to enhance objectivity when assessing the quality of bowel preparation in CC. We herewith provide an accurate model that identifies patients at a higher risk for inadequate cleansing examinations, which paves the way for tailored optimization of bowel preparation protocol for CC in those settings.

\section{Statement of Ethics}

The study protocol conforms to the ethical guidelines of the 1975 Declaration of Helsinki. All patients signed an informed consent form, and consensual contraindications for CC procedure were respected.

Conflict of Interest Statement

There is no conflict of interest to report.

GE Port J Gastroenterol 2022;29:311-321 DOI: $10.1159 / 000518588$ 


\section{Funding Sources}

There is no funding source to report.

\section{Author Contributions}

Rui de Sousa Magalhães - design of the study; collection, statistical analysis, and interpretation of the data; drafting of the article and in the final approval of the article.
Pedro Boal Carvalho - final approval of the article.

Bruno Rosa - conception of the study and final approval of the article.

Maria João Moreira - final approval of the article.

José Cotter - conception of the study and final approval of the article.

\section{References}

1 May FP, Shaukat A. State of the Science on Quality Indicators for Colonoscopy and How to Achieve Them. Am J Gastroenterol. 2020 Aug;115(8):1183-90.

2 Rembacken B, Hassan C, Riemann JF, Chilton A, Rutter M, Dumonceau JM, et al. Quality in screening colonoscopy: position statement of the European Society of Gastrointestinal Endoscopy (ESGE). Endoscopy. 2012 Oct;44(10):957-68.

3 Hassan C, Manning J, Álvarez González MA, Sharma P, Epstein M, Bisschops R. Improved detection of colorectal adenomas by highquality colon cleansing. Endosc Int Open. 2020 Jul;8(7):E928-37.

4 Spada C, Hassan C, Galmiche JP, Neuhaus H, Dumonceau JM, Adler S, et al.; European Society of Gastrointestinal Endoscopy. Colon capsule endoscopy: European Society of Gastrointestinal Endoscopy (ESGE) Guideline. Endoscopy. 2012 May;44(5):527-36.

5 Vuik FE, Nieuwenburg SA, Moen S, Spada C, Senore C, Hassan C, et al. Colon capsule endoscopy in colorectal cancer screening: a systematic review. Endoscopy. 2021 Aug;53(8):815-24.

6 de Sousa Magalhães R, Arieira C, Boal Carvalho P, Rosa B, Moreira MJ, Cotter J. Colon Capsule CLEansing Assessment and Report (CC-CLEAR): a new approach for evaluation of the quality of bowel preparation in capsule colonoscopy. Gastrointest Endosc. 2021 Jan;93(1):212-23.

7 Boal Carvalho P, Rosa B, Dias de Castro F, Moreira MJ, Cotter J. PillCam COLON 2 in Crohn's disease: A new concept of pan-enteric mucosal healing assessment. World J Gastroenterol. 2015 Jun;21(23):7233-41.

8 Rosa BJ, Barbosa M, Magalhães J, Rebelo A, Moreira MJ, Cotter J. Oral purgative and simethicone before small bowel capsule endoscopy. World J Gastrointest Endosc. 2013 Feb;5(2):67-73.

9 Cotter J, de Castro FD, Magalhães J, Moreira MJ, Rosa B. Finding the solution for incomplete small bowel capsule endoscopy. World J Gastrointest Endosc. 2013 Dec;5(12):595-9.

10 Enns RA, Hookey L, Armstrong D, Bernstein CN, Heitman SJ, Teshima C, et al. Clinical practice guidelines for the use of video capsule endoscopy. Gastroenterology. 2017 Feb;152(3):497-514.
11 Cotter J, Magalhães J, de Castro FD, Barbosa M, Carvalho PB, Leite S, et al. Virtual chromoendoscopy in small bowel capsule endoscopy: new light or a cast of shadow? World J Gastrointest Endosc. 2014 Aug;6(8):359-65.

12 Forootan M, Bagheri N, Darvishi M. Chronic constipation: A review of literature. Medicine (Baltimore). 2018 May;97(20):e10631.

13 Wald A, Scarpignato C, Mueller-Lissner S, Kamm MA, Hinkel U, Helfrich I, et al. A multinational survey of prevalence and patterns of laxative use among adults with self-defined constipation. Aliment Pharmacol Ther. 2008 Oct;28(7):917-30.

14 Russo M, Strisciuglio C, Scarpato E, Bruzzese D, Casertano M, Staiano A. Functional Chronic Constipation: Rome III Criteria Versus Rome IV Criteria. I Neurogastroenterol Motil. 2019 Jan;25(1):123-8.

15 Lai EJ, Calderwood AH, Doros G, Fix OK, Jacobson BC. The Boston bowel preparation scale: a valid and reliable instrument for colonoscopy-oriented research. Gastrointest Endosc. 2009 Mar;69(3 Pt 2):620-5.

16 Spada C, Riccioni ME, Hassan C, Petruzziello L, Cesaro P, Costamagna G. PillCam colon capsule endoscopy: a prospective, randomized trial comparing two regimens of preparation. JClin Gastroenterol.2011 Feb;45(2):119_ 24.

17 Kastenberg D, Burch WC Jr, Romeo DP, Kashyap PK, Pound DC, Papageorgiou N, et al. Multicenter, randomized study to optimize bowel preparation for colon capsule endoscopy. World J Gastroenterol. 2017 Dec;23(48):8615-25.

18 Fuccio L, Frazzoni L, Spada C, Mussetto A, Fabbri C, Manno M, et al.; QIPS study group. Factors That Affect Adequacy of Colon Cleansing for Colonoscopy in Hospitalized Patients. Clin Gastroenterol Hepatol. 2021 Feb;19(2):339-348.e7.

19 Dik VK, Moons LM, Hüyük M, van der Schaar P, de Vos Tot Nederveen Cappel WH, Ter Borg PC, et al.; Colonoscopy Quality Initiative. Predicting inadequate bowel preparation for colonoscopy in participants receiving split-dose bowel preparation: development and validation of a prediction score. Gastrointest Endosc. 2015 Mar;81(3):665-72.
20 Yadlapati R, Johnston ER, Gregory DL, Ciolino JD, Cooper A, Keswani RN. Predictors of Inadequate Inpatient Colonoscopy Preparation and Its Association with Hospital Length of Stay and Costs. Dig Dis Sci. 2015 Nov;60(11):3482-90.

21 Gimeno-García AZ, Baute JL, Hernandez G, Morales D, Gonzalez-Pérez CD, NicolásPérez D, et al. Risk factors for inadequate bowel preparation: a validated predictive score. Endoscopy. 2017 Jun;49(6):536-43.

22 Garber A, Sarvepalli S, Burke CA, Bhatt A, Ibrahim M, McMichael J, et al. Modifiable Factors Associated with Quality of Bowel Preparation Among Hospitalized Patients Undergoing Colonoscopy. J Hosp Med. 2019 May;14(5):278-83.

23 Suares NC, Ford AC. Prevalence of, and risk factors for, chronic idiopathic constipation in the community: systematic review and metaanalysis. Am J Gastroenterol. 2011 Sep;106(9):1582-91.

24 Guo X, Shi X, Kang X, Luo H, Wang X, Jia H, et al. Risk Factors Associated with Inadequate Bowel Preparation in Patients with Functional Constipation. Dig Dis Sci. 2020 Apr;65(4):1082-91.

25 Zorzi M, Valiante F, Germanà B, Baldassarre G, Coria B, Rinaldi M, et al.; TriVeP Working Group. Comparison between different colon cleansing products for screening colonoscopy. A noninferiority trial in population-based screening programs in Italy. Endoscopy. 2016 Mar;48(3):223-31.

26 Argüelles-Arias F, San-Juan-Acosta M, Belda A, García-Montes JM, Pellicer F, Polo J, et al. Preparations for colon capsule endoscopy. Prospective and randomized comparative study between two preparations for colon capsule endoscopy: PEG 2 liters + ascorbic acid versus PEG 4 liters. Rev Esp Enferm Dig. 2014 May;106(5):312-7.

27 Martel M, Barkun AN, Menard C, Restellini S, Kherad O, Vanasse A. Split-Dose Preparations Are Superior to Day-Before Bowel Cleansing Regimens: A Meta-analysis. Gastroenterology. 2015 Jul;149(1):79-88.

28 Nguyen DL, Jamal MM, Nguyen ET, Puli SR, Bechtold ML. Low-residue versus clear liquid diet before colonoscopy: a meta-analysis of randomized, controlled trials. Gastrointest Endosc. 2016 Mar;83(3):499-507.e1. 
29 Singhal S, Nigar S, Paleti V, Lane D, Duddempudi $S$. Bowel preparation regimens for colon capsule endoscopy: a review. Therap Adv Gastroenterol. 2014 May;7(3):115-22.

30 Kang SH, Jeen YT, Lee JH, Yoo IK, Lee JM, Kim SH, et al. Comparison of a split-dose bowel preparation with 2 liters of polyethylene glycol plus ascorbic acid and 1 liter of polyethylene glycol plus ascorbic acid and bisacodyl before colonoscopy. Gastrointest Endosc. 2017 Aug;86(2):343-8.

31 Kim SH, Kim ER, Kim K, Kim TJ, Hong SN, Chang DK, et al. Combination of bisacodyl suppository and $1 \mathrm{~L}$ polyethylene glycol plus ascorbic acid is a non-inferior and comfortable regimen compared to $2 \mathrm{~L}$ polyethylene glycol plus ascorbic acid. Dig Endosc. 2020 May;32(4):600-7.
$32 \mathrm{Lu} \mathrm{J}$, Cao Q, Wang X, Pu J, Peng X. Application of Oral Lactulose in Combination With Polyethylene Glycol Electrolyte Powder for Colonoscopy Bowel Preparation in Patients With Constipation. Am J Ther. 2016 JulAug;23(4):e1020-4.

33 Yıldar M, Yaman İ, Başbuğ M, Çavdar F, Topfedaisi H, Derici H. A new approach in bowel preparation before colonoscopy in patients with constipation: A prospective, randomized, investigator-blinded trial. Turk J Surg. 2017 Mar;33(1):29-32.
34 Gkolfakis P, Tziatzios G, Papanikolaou IS, Triantafyllou K. Strategies to Improve Inpatients' Quality of Bowel Preparation for Colonoscopy: A Systematic Review and MetaAnalysis. Gastroenterol Res Pract. 2019 May;2019:5147208.

35 Kamran U, Abbasi A, Tahir I, Hodson J, Siau K. Can adjuncts to bowel preparation for colonoscopy improve patient experience and result in superior bowel cleanliness? A systematic review and meta-analysis. United European Gastroenterol J. 2020 Dec;8(10):121727. 